\title{
Correction to: Maximizing the management of groundwater resources in the Paris-Abu Bayan reclaimed area, Western Desert, Egypt
}

\author{
Maged El Osta ${ }^{1,2}$
}

Published online: 26 November 2018

(C) Saudi Society for Geosciences 2018

Correction to: Arabian Journal of Geosciences (2018) 11: 642 https://doi.org/10.1007/s12517-018-3945-0

The original version of this paper was published with error. The international coordinates of the map located in the right side of the Fig. 1, where the latitude line no. 22 at the bottom of the map should be a straight line. Given in this article is the correct figure.

The online version of the original article can be found at https://oi.org/ $10.1007 / \mathrm{s} 12517-018-3945-0$

\footnotetext{
Maged El Osta

drmagedelosta.edu.alex@hotmail.com

1 Water Research Center, King Abdulaziz University, Jeddah, Saudi Arabia

2 Geology Department, Faculty of Science, Damanhour University, Damanhour, Egypt
} 


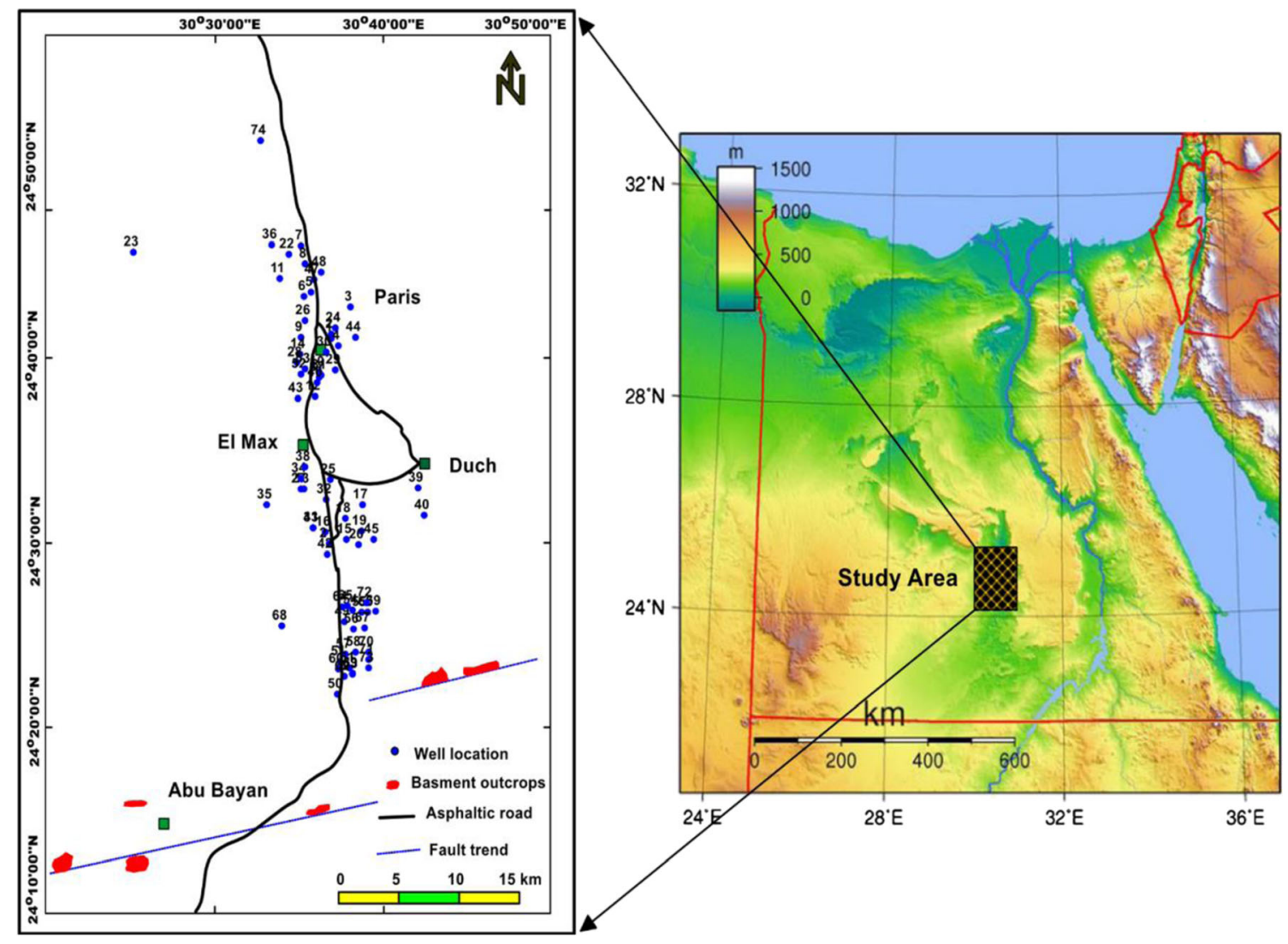

Fig. 1 Map of study area showing location of groundwater wells 